\title{
What the paediatrician should know about paediatric and adolescent gynecology: The perspective of a gynecologist
}

\author{
Victoria Jane Davis MD FRCSC
}

VJ Davis. What the paediatrician should know about paediatric and adolescent gynecology: The perspective of a gynecologist. J Sex Reprod Med 2003;3(3):103-107.

Gynecological problems are common in children but training in this subject is rare during paediatric postgraduate education. Knowledge in this area is important for providing comprehensive health care to children. The article explores the gynecological examination of the child and common gynecological disorders in the paediatric and adolescent age groups. Routine examination of the external genitalia as part of a well-child physical normalizes the examination for the child and helps to inform the physician about the large variations in normal genitals. Many complaints can be dealt with by reassurance, while most others respond to medical therapy and can be dealt with easily by paediatricians. Both young children and adolescents respond positively when allowed to have control over the tempo of the interview and the examination. A positive experience associated with a genital examination will help to open lines of trust. This along with nonjudgmental, open communication, will create educational opportunities to enhance a responsible transition from child to young adult.

Key Words: Gynecology; Vulvar; Paediatric
Ce que le pédiatre devrait savoir sur la gynécologie des enfants et des adolescents : La perspective d'un gynécologue

\begin{abstract}
Les problèmes gynécologiques sont courants chez les enfants, mais la formation à ce sujet se fait rare pendant les études postdoctorales en pédiatrie. Il est important d'avoir des connaissances dans ce domaine pour offrir des soins complets aux enfants. Le présent article porte sur l'examen gynécologique de l'enfant et sur les pathologies gynécologiques courantes chez les enfants et les adolescents. L'examen systématique des organes génitaux externes dans le cadre de l'examen physique d'un enfant en santé normalise l'examen pour l'enfant et contribue à informer le médecin des importantes variations entre les organes génitaux normaux. De nombreux symptômes peuvent être réglés par du réconfort, tandis que la plupart des autres réagissent à la pharmacothérapie et peuvent être facilement traités par les pédiatres. Tant les jeunes enfants que les adolescents réagissent de manière positive lorsqu'on leur permet de contrôler le rythme de l'entrevue et de l'examen. Une expérience positive de l'examen génital contribuera à l'établissement de liens de confiance. Ce phénomène, allié à des communications ouvertes et non critiques, favorise les possibilités de formation afin de promouvoir une transition responsable entre l'enfance et l'âge adulte.
\end{abstract}

Yynecological problems in children are relatively common $J_{\text {in paediatric practice, yet few paediatricians receive formal }}$ exposure to this area during training. Therefore, knowledge and confidence in the area of paediatric and adolescent gynecology are invaluable to the paediatrician. This article explores the gynecological examination of the child and common gynecological disorders in the paediatric and adolescent age groups.

Inspection of the external genitalia as part of a routine wellchild examination normalizes the examination for the child and helps inform the physician about the large variations in the normal growth and development of the reproductive tract, thereby facilitating the recognition of pathology.

EXAMINATION OF THE PREPUBERTAL CHILD

The examination of genitalia begins at birth to check for ambiguities in sex. Beyond the neonate, either the parents will express concerns or a problem will be identified during a wellchild examination. After a complete history from the child and/or parents has been taken, it is important to explain the purpose of the examination and to describe what will take place during the examination. The child must be assured that she is in control and will not be hurt. It is important to respond to any complaints. Because most vulvar disorders can be diagnosed by a systematic inspection of the external genitalia alone, the child can often be told that the examination is only to "take a look". If any instruments or materials are to be used in the examination, the patient should see and touch them. The child should be allowed to keep her top and socks on with a sheet provided. A small anxious child is best evaluated on a seated parent's lap.

The gynecological examination begins with palpation of the chest (Tanner staging of breasts), abdomen and groin (for

Department of Obstetrics and Gynaecology, University of Toronto, Toronto, Ontario

Correspondence and reprints: Dr Victoria Jane Davis, Acting Chief - Section of Paediatric and Adolescent Gynaecology, The Hospital for Sick

Children, 555 University Avenue, Toronto, Ontario M5G 1X8. Telephone 416-813-6188, fax 416-813-7935,

e-mail victoria.davis@sickkids.ca 


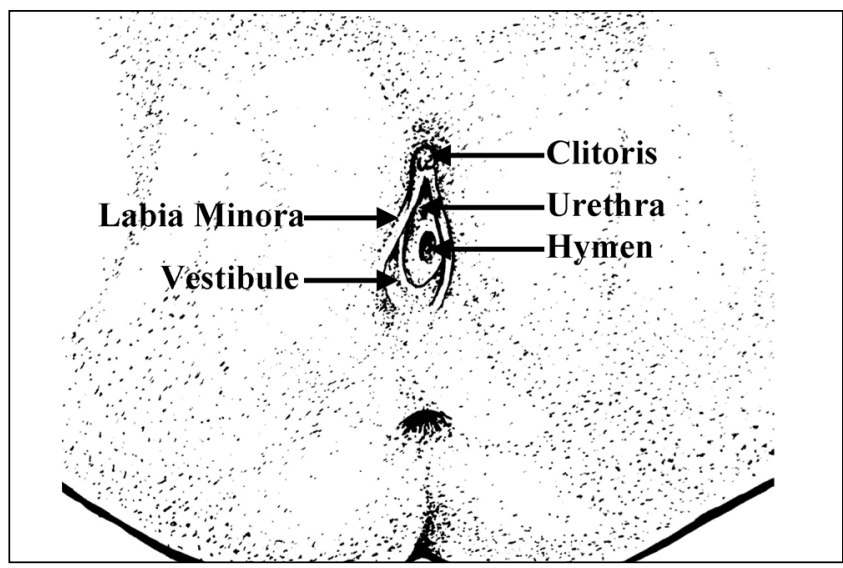

Figure 1) Normal prepubertal external genitalia

nodes). The supine position is used most frequently, with the soles of the feet together and drawn towards the buttocks in a 'frog's-leg' position. A mirror can help the child guide the examination. The child can also be involved in separating her labia. Gentle traction of the labia, in an outwards and supine direction, is often necessary to view the hymenal ring in its entirety and to visualize the lower vagina. Upon inspection of the external genitalia, abnormalities of mons pubis, labia majora (fusion suggests androgen exposure), labia minora, clitoris (size), urethra, vestibule, hymen (patency, notches, scarring), and posterior fourchette (scarring) should be noted (Figure 1). Vaginal cultures can be obtained by irrigating the lower portion of the vagina with sterile saline through a soft red number 12 foley, a catheter from a butterfly intravenous set or with a wetted calgi swab. Vaginoscopy or otoscopic examination (after application of 2\% lidocaine gel) is less traumatic than an examination with a speculum (either nasal or vaginal) because the unestrogenized genital tract is easily damaged. When an adequate examination cannot be performed and pathology is suspected, there should be no hesitation in arranging an examination under anesthesia (EUA).

\section{COMMON GYNECOLOGICAL DISORDERS OF THE PREPUBERTAL CHILD}

Congenital anomalies of the vulva and hymen

Ambiguous genitalia normally present at birth but some abnormalities are subtle and easily missed. In up to $90 \%$ of cases, the cause is congenital adrenal hyperplasia $(\mathrm{CAH})$ in which genital anomalies can range from full masculinization to an almost normal anatomy. Electrolytes will determine if it is a salt wasting form of CAH so measures can be taken to avoid dehydration. The differential diagnosis includes partial androgen insensitivity and other causes of virilization.

Imperforate, microperforate and septate hymen occur in approximately $3 \%$ to $4 \%$ of girls, but surgical intervention is not necessary until menstruation is anticipated.

If there is evidence of congenital anomalies of the reproductive tract, renal tract anomalies should also be ruled out because of the frequent association of anomalies between these systems (1).

\section{Vulvovaginitis}

In the prepubertal child, the labia minora and majora are small and unestrogenized, leaving the introitus and vagina relatively unprotected and easily contaminated with feces or other materials. This commonly leads to vulvovaginitis (pain, dysuria and pruritis) marked by vulvar erythema and excoriations. Discharge is not a primary symptom of vulvitis but rather vaginitis (vulvovaginitis) (2). It must be determined whether the pruritis is vulvar or anal (pinworms); whether the child is seeking relief from symptoms or is masturbating; and whether there is overzealous hygiene or wearing of tight synthetic clothing. The most common causes of vulvitis are poor hygiene, irritation caused by soaps or bubble baths, or infection by respiratory tract organisms (3). Therapy includes lukewarm sitz baths with colloid oatmeal or baking soda, two to three times a day, and the application of barrier or zinc ointments. Topical steroids may be required for a severe, acute episode or antibiotics for a secondary skin infection. Infective causes of vulvitis include Escherichia coli, Haemophilus influenzae, Staphylococcus aureus and non-group A streptococci; however, these bacteria are also found in vaginal cultures from asymptomatic prepubertal girls (4). Improving hygiene is usually all that is required, but if the vulvitis is severe, antibiotics should be considered. Group A streptococcus, with or without evidence of upper respiratory tract involvement, usually presents acutely with dysuria and a severe erythematous vulvitis; there may also be a serosanguineous vaginal discharge which needs to be treated with penicillin, cephalosporin or erythromycin as well as sitz baths and soothing ointments (5). The differential diagnosis includes dermatosis and herpetic vulvitis. Candidiasis can occur shortly after birth (until the maternal estrogens decline) but is rare in immunocompetent, prepubertal girls because yeast cells require an estrogenized epithelium to adhere to and cause pathology (6).

Vaginitis, an inflammation of the vagina, is usually associated with copious asymptomatic discharge, though this may cause secondary chafing or irritation. The differential diagnosis is a single organism infection, foreign body, neoplasia and ectopic ureter. Foreign bodies and vaginal infection with Shigella, Streptococcus or enteric organisms are often associated with a foul-smelling, bloody vaginal discharge. It is important to rule out a sexually transmitted infection when vaginitis is the presenting symptom (6), treat the isolated organism, and, if the vaginal discharge persists, consider vaginoscopy with or without EUA.

A physiological discharge is a clear, odourless mucous discharge that does not cause vulvar irritation under conditions of normal hygiene. This is often seen in newborn females until maternal estrogens have cleared. Physiological discharge recurs around puberty; it may require explanation and reassurance.

\section{Labial adhesions}

Adhesions between the labia minora are caused by irritation of the thin, unestrogenized labia (Figure 2). This condition can be distinguished from imperforate hymen or labioscrotal fusion (androgen associated, midline fusion of external genitals) by the inability to visualize the urethra. If more than $75 \%$ of the labia are closed, it is appropriate to treat this with topical estrogen applied sparingly to the line of adhesion, twice daily, until separation occurs. Estrogen treatment should be continued until the urethra is visualized, as long as there is no evidence of systemic estrogenization (breast bud). Therapy may take up to six weeks (7). Adhesions tend to recur if preventive measures are not taken (ie, gentle labial separation to visualize the urethra with the application of petroleum jelly or barrier 
cream to reduce labial adherence). Additional management includes daily baths, avoidance of irritants such as soapy water or bubble baths, and vulvar 'airing' (a daily period of time when the diaper is removed or not wearing underwear with night clothing). The surgical release of labial adhesions is rarely required.

Well-child examinations of girls should include inspection of the vulva with separation of the labia minora to visualize the introitus (urethra and hymen) to allow early detection and management of labial adhesions, as well as to instruct parents in preventive care.

\section{Lichen sclerosis}

Lichen sclerosis is a vulvar dermatosis that presents with vulvar burning and irritation, and is frequently mistaken for chronic candidiasis infection. Classically, there is an hourglass-shaped whitening around the vulva and anus with loss of definition in the labia and clitoris (8). There may be fissures, punctate hemorrhages, and labial or clitoral adhesion, depending on the stage of the disease. The etiology is unknown but there are inflammatory changes in biopsies; however, a biopsy is not required to make the diagnosis. Although the natural history of lichen sclerosis in children is not well defined, it appears some patients have resolution of the symptoms with menarche. An association between lichen sclerosis and squamous carcinoma of the vulva has been found in adult women, therefore annual checkups should be continued (8). Treatment includes topical steroid ointments (not cream) such as betamethazone valerate, twice daily for two to three weeks, followed by tapering. Often, application once or twice a week keeps the symptoms away. Other measures include cotton underwear, avoidance of soaps and the use of petroleum gel to avoid drying. The differential diagnosis includes atopic dermatitis (eczema), other skin disorders (psoriasis) or systemic diseases (vitiligo, viral illness). A careful history and vulvar inspection will facilitate the diagnosis.

\section{Vaginal bleeding}

Vaginal bleeding (Table 1) in a prepubertal child is always abnormal and is extremely distressing to parents. The most common cause is noninflicted trauma through the child falling on an object in a straddled position. All perineal injuries must be consistent with the mechanism of occurrence, and the possibility of sexual abuse must be ruled out, especially if the hymen is involved. If the lesion can be visualized and has stopped bleeding with conservative measures, the child can go home after spontaneous urination. For three or four days the management includes sitz baths two to three times a day (lukewarm, plain water), topical estrogen cream once or twice daily and analgesia (acetaminophen, topical anesthetic). If the extent of the lesion cannot be visualized or a penetrating injury is suspected, an EUA is necessary. Surgical intervention is based on the need for hemostasis, after failure of adequate conservative therapy (pressure, ice packs), or a large lesion (over $2 \mathrm{~cm}$ ). Hematomas that are not expanding can be treated with ice packs and observed. Large, expanding hematomas need to be surgically evacuated and the bleeding controlled.

All health care providers need to be aware of the signs and symptoms of sexual abuse. To assess for sexual abuse, the examiner must be aware of the multitude of normal hymenal variants and those hymenal lesions consistent with penetration, as well as other factors that suggest abuse. As a general rule,

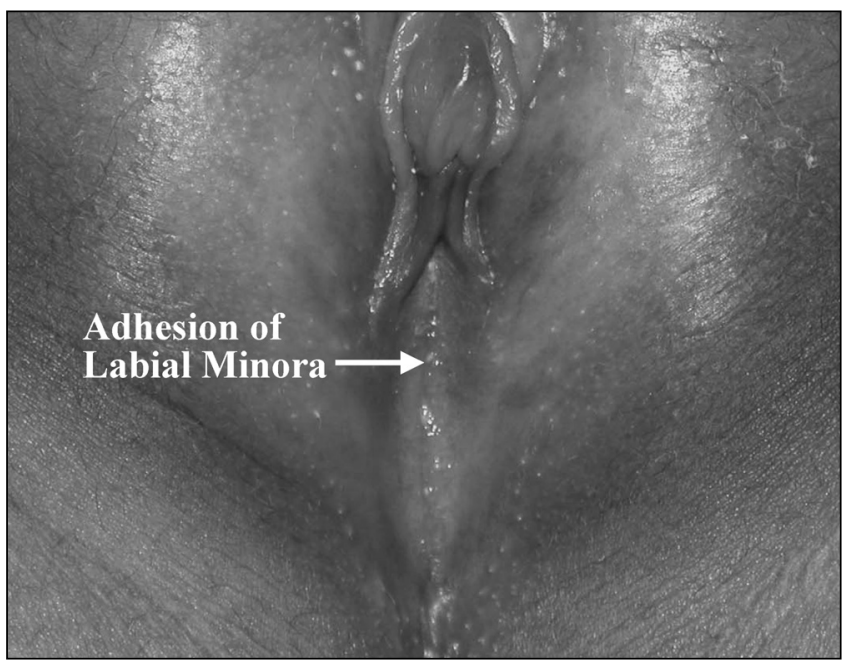

Figure 2) Labial adhesions

\begin{tabular}{|c|c|}
\hline Trauma & Intentional and nonintentional \\
\hline Infectious vaginitis & Shigella, Streptococcus, enteric organisms \\
\hline $\begin{array}{l}\text { Intravaginal foreign } \\
\text { body }\end{array}$ & $\begin{array}{l}\text { Malodorous discharge that causes a secondary } \\
\text { vulvitis }\end{array}$ \\
\hline Urethral prolapse & $\begin{array}{l}\text { Often painless, purple, introital mass. More } \\
\text { common among African-Americans. A physical } \\
\text { examination is paramount to diagnosis }\end{array}$ \\
\hline Precocious puberty & Signs of systemic estrogen exposure, growth spurt \\
\hline Vaginal tumor & $\begin{array}{l}\text { Rare, an examination under anaesthesia is needed } \\
\text { if vaginal bleeding persists without diagnosis }\end{array}$ \\
\hline
\end{tabular}

hymenal irregularities, notches and scarring in the lower half of the hymen plus or minus scarring in the posterior fourchette are suspicious of penetration (9). If there are concerns about abuse based on history, child behaviour or physical examination, a referral to child protective agencies should be made.

Urethral prolapse (circumferential eversion of the urethral mucosa) usually presents with painless vaginal bleeding; occasionally dysuria and frequency, and on rare occasions, urinary retention (Figure 3). The etiology of urethral prolapse is unclear but is more common in African-American girls around five years old (10). The initial diagnosis is incorrect in up to $50 \%$ of cases, and is often confused with sexual abuse or vaginal neoplasm (11). The distinguishing feature is the anterior location of a fleshy mass that can be necrotic and purple. The prolapse may extend over the hymen, obscuring it from view, so care must be taken to identify the hymen to define the anatomy. Treatment consists of topical estrogen and sitz baths. Excision is required in over $50 \%$ of cases, depending on the series and the length of estrogen treatment. If six weeks of therapy with topical estrogen, twice daily, does not significantly improve the prolapse or if the prolapse recurs, surgery is necessary.

A foreign body within the vagina can present with vaginal bleeding as one of the symptoms along with a profuse, foul smelling vaginal discharge plus or minus vulvitis. A small ball of toilet paper is the most common offender and can often be removed in the office using topical anesthesia and vaginal 


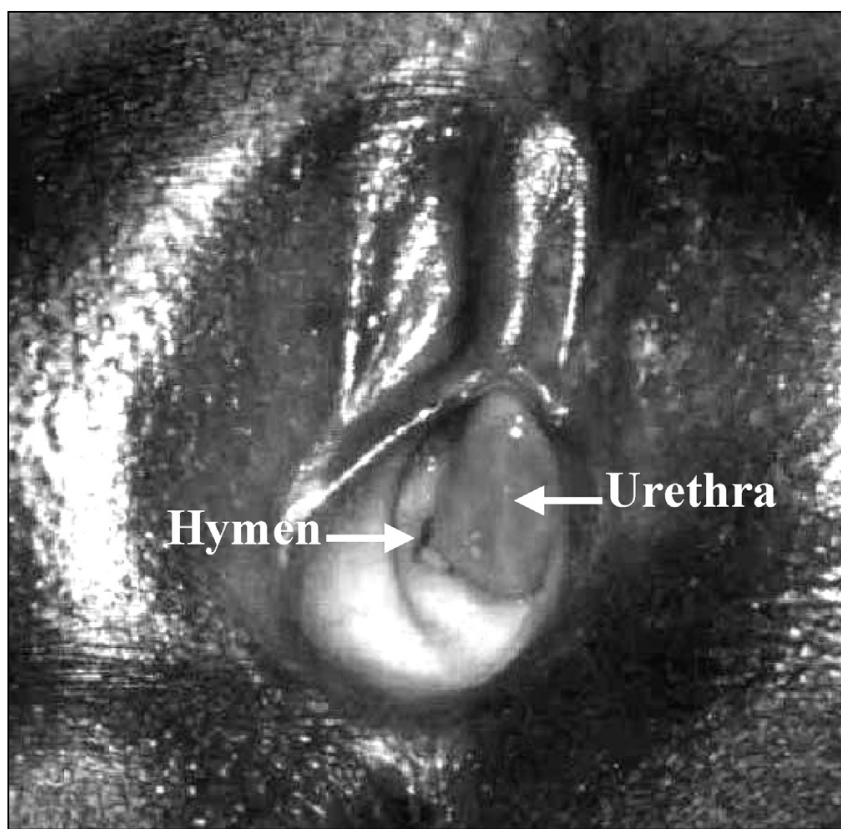

Figure 3) Urethral prolapse

irrigation with an $8 \mathrm{~mm}$ or $10 \mathrm{~mm}$ paediatric catheter and warm saline. Otherwise, an EUA will be needed to remove the foreign body. An x-ray or ultrasound will not detect a foreign body and are not recommended.

Vaginal bleeding in the absence of systemic estrogen exposure is not precocious puberty, and other causes of vaginal bleeding must be excluded. If a cause for vaginal bleeding cannot be identified, an EUA is warranted to rule out tumors of the vagina such as sarcoma botryoides or endodermal sinus tumors. Although tumors of the vagina are rare in prepubertal girls, they occur in up to $12 \%$ of those with vaginal bleeding.

\section{PUBERTY}

The average onset of pubertal changes occurs between the ages of nine to 11 and usually begins with breast development, closely followed by the appearance of pubic hair. Menarche typically occurs approximately two years after thelarche and at the average age of 11.4 years. Pubertal changes such as a growth spurt, thelarche or adrenarche before the age of six years in African-American girls and seven in Caucasian girls is considered precocious (12). Isolated thelarche or adrenarche is attributed to high-end organ sensitivity to low levels of circulating hormone; however, it should be followed for progression into true precocious puberty marked by accelerated growth (increased bone age) and evidence of multi-organ stimulation. Once true precocious puberty is established, through the gonadotropin stimulation test, the rate of progress of pubertal changes, the estimated adult height, and the psychological maturity of the child, as well as parental wishes, will determine if treatment is appropriate.

The initial menstrual cycles are anovulatory and, therefore, tend to be irregular for almost two years; reassurance is all that is needed if the patient or their parents are seeking advice. Primary dysmenorrhea is a feature of ovulation, so pain occurring with the initiation of menstruation should be investigated with an ultrasound to rule out an obstructed mullerian anom- aly - just as heavy bleeding with menstruation should alert a physician to the possibility of a coagulation disorder. Menstrual irregularity and dysmenorrhea are common symptoms in adolescent females; if pathology is ruled out and the symptoms are causing significant distress, treatment should be considered. Nonsteroidal anti-inflammatoy drugs (NSAIDs) are useful to decrease the amount of pain and blood flow in most women but will not regulate their cycles. It is important to take the NSAID as soon as menstruation begins and to follow the dosing schedule to the letter to maximize benefit, usually treatment is only needed for two to three days. The oral contraceptive regulates the menstrual cycle and decreases bleeding and pain. Parents often are concerned that the use of an oral contraceptive will cause their daughter to become sexually active, but literature and experience does not support this. Use of an oral contraceptive to regulate menstruation and allow the hypothalamic-pituitary-ovarian axis to mature is appropriate and may require only six to 12 months of therapy.

\section{THE ADOLESCENT}

Adolescents want to feel that they are in control, and that their health care provider is nonjudgmental and will maintain confidentiality at all cost. In addition, adolescents need to hear that their care is confidential; however, there are some instances where confidentiality cannot be guaranteed, such as suspected abuse. Parental involvement should always be discussed and encouraged. Communication skills are paramount to a therapeutic relationship with any patient but especially with the adolescent. The health care provider should avoid patronization and be able to freely discuss sexuality without judgment.

Up to $50 \%$ of grade 11 students report having had sex. Some adolescents may present with menstrual disorders to access contraceptives. An open question about sexual activity, in the absence of parents, is needed to elicit a truthful response. Oral contraceptives can be prescribed without a Pap smear but the need for this examination, in addition to testing for sexually transmitted infections, as a part of well-woman care should be discussed. The pelvic examination can be delayed until the young woman is comfortable with the idea. Pamphlets and handouts are often useful to provide additional information on contraception, safer sex and Pap smears; pamphlets in the washroom can be taken and read in privacy. A Pap smear is not necessary until an adolescent is having intercourse. When discussing safe sex, the use of condoms should be promoted to reduce the risk of sexually transmitted infections, which have the highest rates in the 15- to 24-year-old age group. Another important topic to be discussed is emergency contraception and how to access it, or providing a prescription in advance of need. Knowledge of where to find local family planning clinics, what services are provided and their hours of operation is also an asset.

\section{SUMMARY}

Gynecological complaints are common in young girls and knowledge in this area is important to providing comprehensive health care to children. Many complaints can be dealt with by reassurance, whereas most others respond to medical therapy. If the vulva is routinely examined as part of a wellchild examination, the anxiety around these examinations will be reduced. Both young children and adolescents respond positively when allowed to have control over the tempo of the 
interview and the examination. An open, nonjudgmental approach will facilitate a therapeutic bond. This may lead to educational opportunities that result in an empowered adolescent and responsible sexuality in the young adult.

\section{REFERENCES}

1. Edmonds DK. Congenital malformations of the reproductive tract. Obstet Gynecol Clin North Am 2000;27:49-62.

2. Altchek A. Pediatric vulvovaginitis. J Reprod Med 1984:29:359-75.

3. Herman-Giddens ME, Bernson NL. Harmful genital care practices in children. JAMA 1989;261:577-9.

4. Gerstner GJ, Grunberger W, Boschitsch E, Rotter M. Vaginal organisms in prepubertal children with and without vulvovaginitis. A vaginoscopic study. Arch Gynecol 1982;23:247-52.

5. Schwartz RH, Wientzen RL, Barsanti RG. Vulvovaginitis in prepubertal girls: the importance of group A streptococcus. South Med J 1982;75:446-7.

6. Pokorny SF. Prepubertal vulvovaginopathies. Obstet Gynecol Clin North Am 1992;19:39-58.
7. Davis VJ, Coates M. Medical management of labial adhesions. North American Society of Pediatric and Adolescent Gynecology Annual Meeting, Miami, 2001. (Abst) (In press)

8. Leibowitch M. Lichen sclerosis. Semin Dermatol 1996;15:42-6.

9. McCann J. The appearance of acute, healing, and healed anogenital trauma. Child Abuse Negl 1998;22:605-15.

10. Rudin JE, Geldt VG, Alecseev EB. Prolapse of urethral mucosa in white female children: Experience with 58 cases. J Ped Surgery 1997;32:423-5.

11. Anveden-Hertzberg L, Gauderer MWL, Elder JS. Urethral prolapse: An often misdiagnosed cause of urogenital bleeding in girls. Pediatr Emerg Care 1995;11:212-4

12. Herman-Giddens ME, Slora EJ, Wasserman RC, et al. Secondary sexual characteristics and menses in young girls seen in office practice: A study from the Pediatric Research in Office Settings network. Pediatrics 1997;999:505-12.

This article originally appeared in Paediatrics $\mathcal{E}$ Child Health 2003;8(8):491-495. 